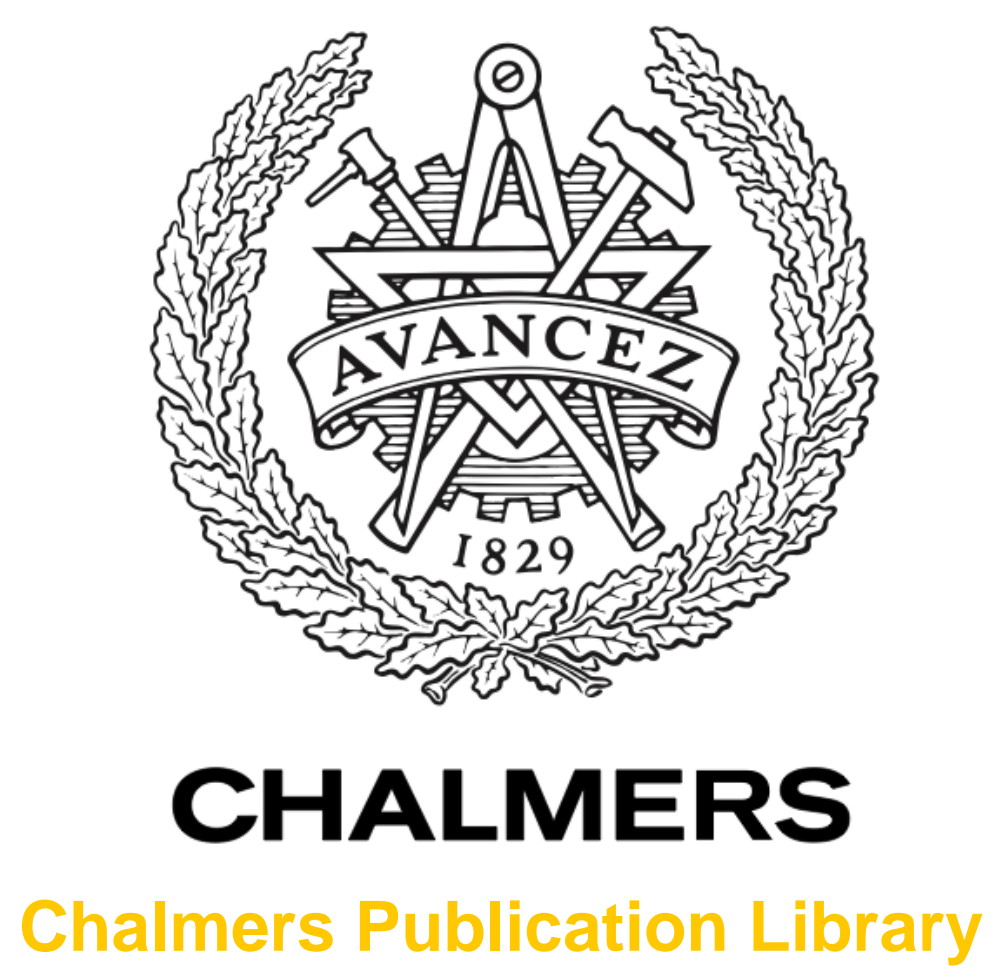

Mono- and Bistatic UHF-Band SAR Measurements of a Hemi-Boreal Forest

This document has been downloaded from Chalmers Publication Library (CPL). It is the author's version of a work that was accepted for publication in:

IEEE International Geoscience and Remote Sensing Symposium

Citation for the published paper:

Ulander, L. ; Soja, M. ; Gustavsson, A. et al. (2015) "Mono- and Bistatic UHF-Band SAR

Measurements of a Hemi-Boreal Forest". IEEE International Geoscience and Remote

Sensing Symposium

Downloaded from: http://publications.lib.chalmers.se/publication/226250

Notice: Changes introduced as a result of publishing processes such as copy-editing and formatting may not be reflected in this document. For a definitive version of this work, please refer to the published source. Please note that access to the published version might require a subscription.

Chalmers Publication Library (CPL) offers the possibility of retrieving research publications produced at Chalmers University of Technology. It covers all types of publications: articles, dissertations, licentiate theses, masters theses, conference papers, reports etc. Since 2006 it is the official tool for Chalmers official publication statistics. To ensure that Chalmers research results are disseminated as widely as possible, an Open Access Policy has been adopted.

The CPL service is administrated and maintained by Chalmers Library. 


\title{
MONO- AND BISTATIC UHF-BAND SAR MEASUREMENTS OF A HEMI-BOREAL FOREST
}

\author{
Lars M. H. Ulander ${ }^{1,2}$, Maciej J. Soja ${ }^{2}$, Anders Gustavsson ${ }^{1}$, Erik Blomberg $^{2}$, and Johan E. S. Fransson ${ }^{3}$ \\ ${ }^{1}$ Swedish Defence Research Agency (FOI), Linköping, Sweden \\ ${ }^{2}$ Chalmers University of Technology, Gothenburg, Sweden \\ ${ }^{3}$ Swedish University of Agricultural Sciences, Umeå, Sweden
}

\begin{abstract}
In this paper, the potential of mono- and bistatic HHpolarized UHF-band SAR imagery for mapping of a hemiboreal forest is studied. SAR data have been acquired with the two airborne SAR sensors LORA and SETHI during a joint FOI-ONERA campaign conducted in 2010. Three acquisition modes are compared: monostatic, quasimonostatic (difference in elevation angle around $0^{\circ}$ ) and bistatic (difference in elevation angle around $6^{\circ}$ ). Images acquired at two perpendicular flight headings are used, i.e. $178^{\circ}$ and $268^{\circ}$, to evaluate the influence of topography, which often has an aggravating effect on forest variable estimation. It is observed that for the quasi-monostatic and bistatic acquisitions, the influence of ground topography is lower compared to the monostatic acquisition. A linear regression model is used to explain the dependence of the backscattering coefficient on the logarithm of biomass, and it is observed that the estimated intercept and slope are similar for the two headings only in the case of quasi-monostatic and bistatic acquisitions, of which the latter features the lowest error and the highest coefficient of determination $(0.73$ and 0.70 , respectively, for headings $178^{\circ}$ and $268^{\circ}$ ).
\end{abstract}

Index Terms - bistatic, SAR, forest, backscatter, UHF, LORA, SETHI

\section{INTRODUCTION}

Bistatic SAR imaging has been actively researched during the last decades [1]. Several bistatic SAR experiments at X-band using two airborne systems have been reported [2-4]. More recently, airborne bistatic SAR imaging has also been demonstrated in the UHF-band [5-7] as well as in the VHFband [8]. The primary objective of the VHF/UHF-band experiments has been to investigate the possible improvement in detecting vehicles concealed in forests, i.e. to exploit the reduction of forest double-bounce scattering by separating the transmitter and receiver in elevation [9].

In this paper, we will compare HH-polarized UHF-band mono- and bistatic SAR imagery of a hemi-boreal forest and compare it with available reference data, derived from both in situ measurements and airborne laser scanning (ALS) data.

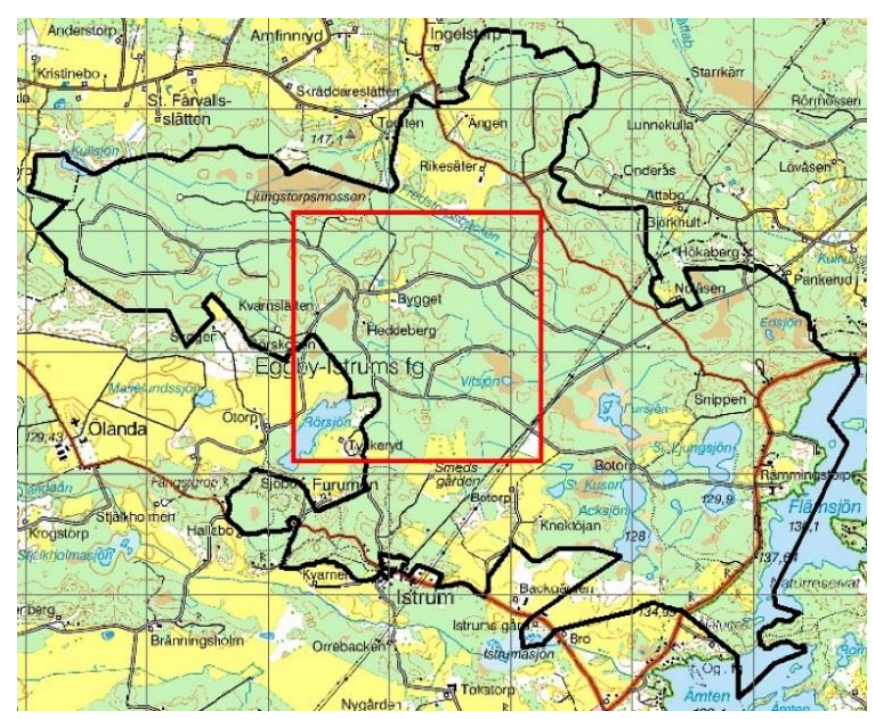

Fig. 1. The Remningstorp border is depicted in black. The red square outlines the $2 \mathrm{~km} \times 2 \mathrm{~km}$ forest area studied in this paper. (Map: (C) Lantmäteriet Dnr: R50051369_150001).

\section{REFERENCE DATA}

Remningstorp is located in southern Sweden $\left(58^{\circ} 28^{\prime} \mathrm{N}\right.$, $\left.13^{\circ} 38^{\prime} \mathrm{E}\right)$. The estate consists of about 1200 ha of forest land. The forested area is classified as hemi-boreal with Norway spruce (Picea abies), Scots pine (Pinus sylvestris) and birch (Betula spp.) as the dominant species. It is mainly a production forest with a range of stem volume conditions up to a maximum value of about $620 \mathrm{~m}^{3} / \mathrm{ha}$. The area is overall rather flat with a topographic elevation range of about $20 \mathrm{~m}$, i.e. between $125 \mathrm{~m}$ and $145 \mathrm{~m}$ above sea level (a.s.l.). However, local ground slopes are in some areas sufficient to give an impact on the forest backscatter despite the small range of elevation variation. Ground slopes at stand level are found to be lower than $5^{\circ}$, computed from a $50 \mathrm{~m} \times 50 \mathrm{~m}$ digital terrain model (DTM).

The estate border is outlined on the map in Fig. 1. The box overlaid on the same map corresponds to the SAR imaged area indicated in Fig. 2 and fully covered in Fig. 3. This area is in focus for the analysis presented in this paper. 

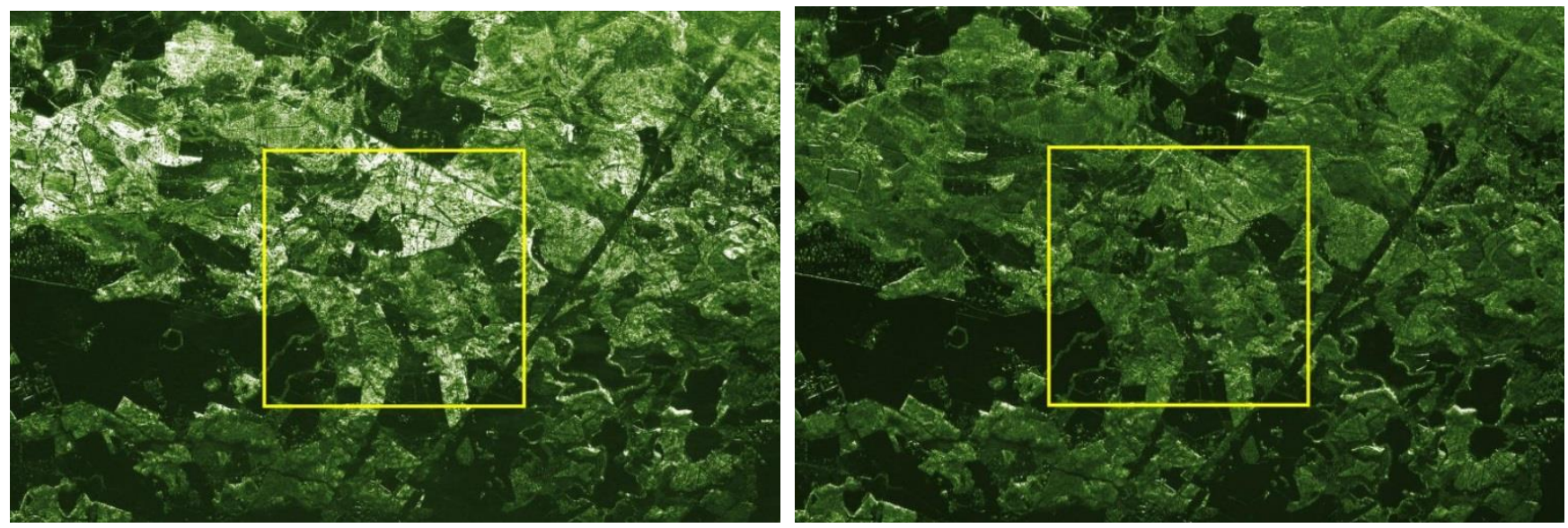

Fig. 2. HH-polarized UHF-band SAR images collected for flight heading $268^{\circ}$ (left: truly monostatic, right: bistatic with elevation angle difference of $6^{\circ}$ ). Bright features are mainly forested areas and dark areas are lakes or open fields. The image size is $6 \mathrm{~km} \times 4 \mathrm{~km}$. The yellow squares corresponds to the ground areas shown in Fig. 3, also marked in red on the map in Fig. 1.

Field inventories at Remningstorp were conducted in autumn 2010 and spring 2011. In total, 212 circular field plots with a radius of $10 \mathrm{~m}$ and distributed in a systematic grid over the entire test site were inventoried. For each plot, all trees with a diameter at breast height (dbh) higher than $5 \mathrm{~cm}$ were calipered, and tree species were determined. Height was measured for a subset of roughly $10 \%$ of the trees. Estimates of above-ground dry biomass have been made from the in situ data using the Heureka system developed at the Swedish University of Agricultural Sciences [10].

ALS data were collected over Remningstorp on the $29^{\text {th }}$ of August 2010. From the ALS data, $10 \mathrm{~m} \times 10 \mathrm{~m}$ maps of different lidar metrics were derived, including metrics of canopy height and canopy cover. A map of above-ground biomass was then created using regression analysis based on ALS data and the 212 inventoried plots. The uncertainty of the biomass map was estimated to roughly $13 \%$.

The Remningstorp test site has been divided into 665 delineated areas, according to land use, forest type, etc. In total, 148 of these areas are forest stands located within the region outlined in Fig. 1. These stands will be used in the subsequent stand-level analysis.

\section{UHF-BAND SAR DATA}

Flight campaigns to investigate bistatic SAR imaging at the UHF-band and HH-polarization have been carried out using the FOI airborne system LORA and the French airborne sensor SETHI developed and operated by ONERA. A waveform covering $222-460 \mathrm{MHz}$ and generated using a stepped frequency scheme was used. The synchronization was accomplished using the GPS based 1-PPS signal and a disciplined $10 \mathrm{MHz}$ reference oscillator instrumented in each radar system. A proof-of-concept with both systems airborne was conducted in France in 2009 [5].
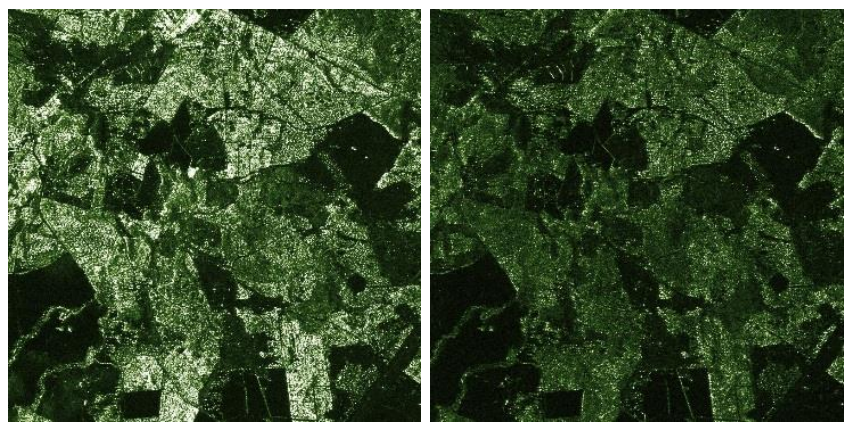

Fig. 3. HH-polarized UHF-band SAR images collected for flight heading $178^{\circ}$ (left: truly monostatic, right: bistatic with elevation angle difference of $6^{\circ}$ ). The image size is $2 \mathrm{~km} \times 2 \mathrm{~km}$ and the area covered is the central part marked in Figs. 1 and 2.

The 2009 results motivated the launch of a major bistatic SAR campaign with LORA and SETHI that took place in Sweden in the fall of 2010 [6-7]. The objective was to investigate the capability of foliage penetration and detection of concealed targets using both mono- and bistatic imaging geometries. The platform acting transmitter was in general positioned closer to the illuminated ground scene to reduce the level of the direct signal in the bistatic receiver.

Two different test sites in southern Sweden were used. The UHF-band SAR data acquired at Remningstorp are in focus in this paper. This test site exhibits a large variability of hemi-boreal forest characteristics and good ground truth data of various forest variables are available. The area was selected for SAR imaging to enable detailed investigations on mono- and bistatic forest clutter. No ground targets were, thus, deployed under foliage at this test site. The forest clutter is of no value and should be suppressed in the concealed target detection application. For forest variable retrieval, on the other hand, forest clutter is the data source to use and analyze. 

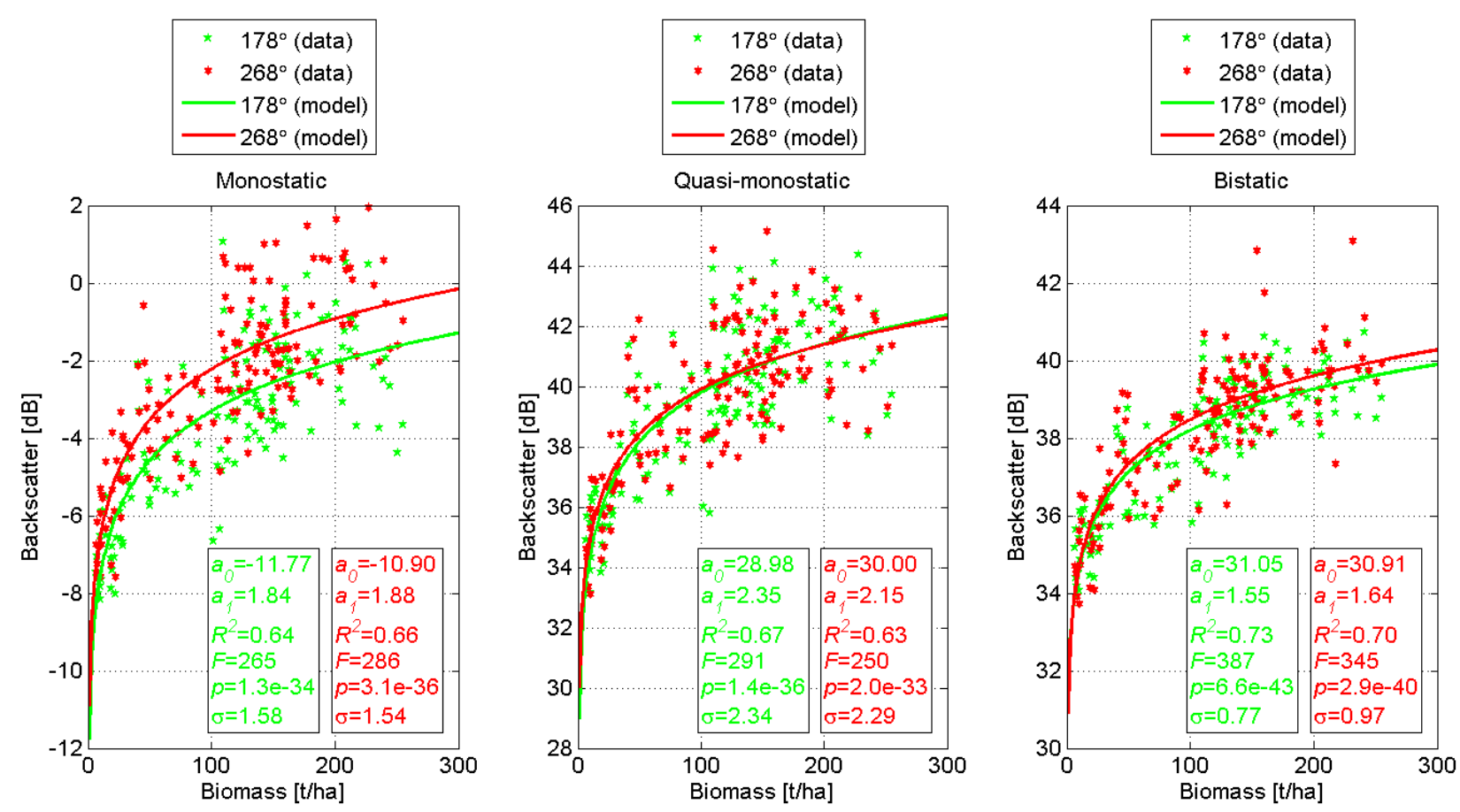

Fig. 4. Plots showing the dependence of the backscattering coefficient on biomass for the 148 stands within the studied area (red square in Fig. 1). Solid lines show the fitted forward model (1). Parameters $a_{0}$ and $a_{1}$ are intercept and slope of the model, $R^{2}$ is the coefficient of determination, $F$ is the value of the F-statistic and $p$ is the corresponding probability, and $\sigma$ is an estimate of the standard deviation.

Nine bistatic imaging passes were undertaken in Remningstorp, with eight along linear tracks and one using a circular track. For the linear tracks, two different flight headings were used as well as a total of three acquisition modes: monostatic, quasi-monostatic (with elevation angle difference around $0^{\circ}$ ), and bistatic (with elevation angle difference around $6^{\circ}$ ). The four imaging passes along linear tracks for the two platforms were repeated with LORA or SETHI acting illuminator of the ground scene and simultaneously gathering the monostatic SAR data set.

SAR data analyzed here will be based on monostatic, quasi-monostatic and bistatic registrations made with LORA's receiver from the linear tracks. Typical differences in mono- and bistatic forest backscattering characteristics will be illustrated by showing SAR image examples from the test site.

\section{MONO- AND BISTATIC IMAGE EXAMPLES}

The LORA SAR processing scheme includes pulsecompression, radio-frequency interference (RFI) filtering, and backprojection image formation. Phase-tracking based on the received direct signal and GPS data is the main block added for the more demanding bistatic SAR processing.
Mono- and bistatic images for the two different flight headings are shown in Figs. 2 and 3, i.e. heading $268^{\circ}$ and $178^{\circ}$, respectively. The ground area covered in Fig. 2 includes the Remningstorp estate border fully to the west, while some minor parts are missing to the north, south and east when compared to the map in Fig. 1. The yellow boxes in Fig. 2 indicate the corresponding areas mapped from the other flight heading and presented in Fig. 3. Two $5 \mathrm{~m}$ large trihedrals were deployed in the open at the test site but only oriented optimally for flight heading $178^{\circ}$. In addition, only one of them is located within the $2 \mathrm{~km} \times 2 \mathrm{~km}$ large sub-area investigated here and encompassed by the SAR scenes found in Fig. 3.

The most striking difference in Figs. 2 and 3 is the reduction of the strongest scatterers found in the monostatic images when compared to the corresponding bistatic signatures. The strongest scatterers in the monostatic images are caused by double-bounce scattering between the ground and the trees. It is well-known that monostatic UHF-band SAR images become sensitive to topographic slopes for $\mathrm{HH}-$ polarization [11]. The bistatic images show less sensitivity to topographic slopes which is consistent with the reduction in double-bounce scattering. 


\section{DEPENDENCE ON BIOMASS}

Stand level intensity estimates were computed by averaging all pixels within each of the 148 stands imaged. Stand-level biomass estimates were computed in the same way from the biomass map. It should be noted that no absolute calibration procedure has been applied on any of the SAR images generated.

A linear forward model was used to explain the dependence of the backscattering coefficient $\sigma_{\mathrm{HH}}^{0}$ (in decibels) on the logarithm of biomass:

$$
\left[\sigma_{\mathrm{HH}}^{0}\right]_{\mathrm{dB}}=a_{0}+a_{1} \cdot \ln B
$$

where $a_{0}$ is the intercept, $a_{1}$ is the slope, and $B$ is biomass (in tons per hectare). To evaluate the goodness-of-fit, the standard F-statistic is used, together with the coefficient of determination $R^{2}$ and the root mean square error (RMSE) $\sigma$.

In Fig. 4, fitting results for model (1) are shown, together with the computed stand-level averages, for three acquisitions scenarios (monostatic, quasi-monostatic, and bistatic) and two flight headings. It is observed, that the difference between the two headings is largest for the monostatic acquisition, hinting that the influence of topography also is the largest. For the quasi-monostatic and bistatic acquisitions, the double-bounce interaction is reduced and the influence of topography is lower. Therefore, the models for the two different headings are more similar. Additionally, it can be observed that the error $\sigma$ is lowest for the bistatic case and the simple model (1) can explain over $70 \%$ of the variations observed in the data.

\section{CONCLUSIONS}

The experiment shows the advantage of bistatic acquisitions for forest mapping in general and biomass estimation in particular, as the influence of topography is decreased by decreasing the contribution of the double-bounce, groundtrunk interaction to the total backscattering. The forward model predicting backscatter from biomass is less dependent on the flight heading and more dependent on biomass.

\section{REFERENCES}

[1] B.D. Rigling, "Spotlight Synthetic Aperture Radar," in N.J. Willis and H.D. Griffiths, Advances in Bistatic Radar, SciTech 2007.

[2] I. Walterscheid, J.H.G. Ender, A.R. Brenner, and O. Loffeld, "Bistatic SAR processing and experiments," IEEE Transactions on Geoscience and Remote Sensing, vol. 44, no. 10, pp. 2710-2717, 2006.

[3] G. Yates, A.M. Horne, A.P. Blake, and R. Middleton, "Bistatic SAR image formation," IEE Proceedings - Radar, Sonar and Navigation, vol. 153, no. 3, pp. 208-213, 2006.
[4] P. Dubois-Fernandez, H. Cantalloube, B. Vaizan, G. Krieger, R. Horn, M. Wendler, and V. Giroux, "ONERA-DLR bistatic SAR campaign: planning, data acquisition, and first analysis of bistatic scattering behaviour of natural and urban targets," IEE Proceedings - Radar, Sonar and Navigation, vol. 153, no. 3, pp. 214-223, 2006.

[5] R. Baqué, P. Dreuillet, O. Ruault du Plessis, H. Cantalloube, L. Ulander, G. Stenström, T. Jonsson, and A. Gustavsson, "LORAMbis. A bistatic VHF/UHF SAR experiment for FOPEN," Proc. Radar 2010, 2010 IEEE Radar Conference, Washington, D.C., 10-14 May 2010, pp. 832-837.

[6] L.M.H. Ulander, R. Baqué, H. Cantalloube, P. Dreuillet, B. Flood, P.-O. Frölind, A. Gustavsson, T. Jonsson, B. Larsson, D. Murdin, R. Ragnarsson, O. Ruault du Plessis, and G. Stenström, "Observations of clutter suppression in bistatic VHF/UHF-band synthetic-aperture radar," Proc. Algorithms for Synthetic Aperture Radar Imagery XVIII, Orlando, FL, 25-29 April 2011, SPIE vol. 8051, pp. $80510 \mathrm{H}-1$ - 80510H-9.

[7] L.M.H. Ulander, B. Flood, P.-O. Frölind, A. Gustavsson, T. Jonsson, B. Larsson, G. Stenström, R. Ragnarsson, R. Baqué, O. Ruault du Plessis, G. Bonin, H. Oriot, and, P. Dreuillet, "Bistatic VHF/UHF-band airborne SAR experiment," Proc. Radar 2012, International Conference on Radar Systems, Glasgow, UK, 22-25 October 2012, 6 pages.

[8] L.M.H. Ulander, A. Gustavsson, T. Jonsson, R. Ragnarsson, and G. Stenström, "Development of CARINA bistatic VHF-band SAR," Proc. RADAR'14, International Radar Conference 2014, Lille, France, 13-17 October 2014, 4 pages.

[9] L.M.H. Ulander and T. Martin, "Bistatic ultra-wideband SAR for imaging of ground targets under foliage," Proc. 2005 IEEE International Radar Conference, Arlington, VA, 9-12 May 2005, pp. 419-423.

[10] P. Wikström, L. Edenius, B. Elfving, L.O. Eriksson, T. Lämås, J. Sonesson, K. Öhman, J. Wallerman, C. Waller, and F. Klintebäck, "The Heureka forestry decision support system: An overview," Mathematical and Computational Forestry \& Natural-Resource Sciences, vol. 3, no. 2, pp. 87-94, 2011.

[11] M.J. Soja, G. Sandberg, and L.M.H. Ulander, "Regressionbased retrieval of boreal forest biomass in sloping terrain using Pband SAR backscatter intensity data," IEEE Transactions on Geoscience and Remote Sensing, vol. 51, no. 5, pp. 2646-2665, 2013. 